A version of this paper appears in Fabrice Correia and Andrea Iacona (eds.), Around the Tree: Semantic and Metaphysical Issues Concerning Branching and the Open Future (Springer, 2012), pp. 127-141.

\title{
The Truth About the Past and the Future
}

\author{
Ned Markosian
}

\begin{abstract}
This paper is about The Truthmaker Problem for Presentism. I spell out a solution to the problem that involves appealing to indeterministic laws of nature and branching semantics for past- and future-tensed sentences. Then I discuss a potential glitch for this solution, and propose a way to get around that glitch. Finally, I consider some likely objections to the view offered here, as well as replies to those objections.
\end{abstract}

\section{Introduction}

This paper is about The Truthmaker Problem for Presentism. Presentism is a version of The A-Theory of Time, according to which putative temporal properties such as pastness, presentness, and futurity (as well as their metric variants: being-two-days-past, being-one-hour-future, etc.) are genuine and unanalyzable properties whose exemplifications by times, events, and things is an objective, mind-independent feature of the world. ${ }^{1}$ But according to Presentism, it is not merely that these putative properties are real. It is also that they have great ontological significance. For Presentism is the view that the only objects that exist at any given time are objects that are present at that time. That is, according to Presentism, the correct ontology of the world is subject to change over time, and is such that it never contains any object that lacks the property of being present. Thus, Socrates used to be included in the correct ontology, and you did not - but now you are in and Socrates is out. ${ }^{2}$

The Truthmaker Problem for Presentism begins with the popular idea that truths must have truthmakers - things or facts or whatever that make them true. This idea is then combined with the intuitive thought that there are lots

\footnotetext{
${ }^{1}$ For more on The A-Theory and its rival, The B-Theory, see Prior, Past, Present and Future, and Markosian "How Fast Does Time Pass?"

${ }^{2}$ For more on Presentism, see Markosian, "A Defense of Presentism."
} 
of truths about the past and the future. For example, it seems clear that it is true now that there were once dinosaurs roaming the planet, and that there will one day be human outposts on Mars. The problem is that there do not seem to be enough truthmakers in the Presentist's ontology for all of these truths about the past and the future. ${ }^{3}$

In what follows I will offer a "branching time" solution to this problem that strikes me as a very natural and simple one, even though it has not yet been defended in the literature. I will also discuss a potential glitch for this natural solution, and I'll try to show how the glitch can be fixed. Finally, I will discuss several objections to the solution that I am offering.

\section{Presentism and its Rivals}

Even though Presentism is a version of The A-Theory of Time, it is possible to capture the dispute between Presentists and their rivals in a way that does not presuppose The A-Theory. All we need is a way to distinguish between objects that are present at a time (the way you are present right now) and objects that are not present at a time (the way Socrates is not present right now). But talk of an object's being present at a time need not be understood in terms of the A-Theorist's controversial property presentness. There is an alternative, B-Theory-friendly way to frame the issue, in terms of the twoplace relation, located at, that an object or event can stand in to a time. Instead of saying that you now have the property of being present while Socrates does not, the B-Theorist can say that you are located at the current time while Socrates is located only at certain earlier times. And since the relevant two place relation, located at, is one that everyone (A-Theorists, B-Theorists, Presentists, opponents of Presentism) should believe in, we can formulate Presentism and its main rivals in terms of this relation, in the following, neutral way.

Presentism: What exists is liable to change over time. For any time, $t$, the objects that exist at $t$ are all and only the objects that are located at $t$.

3 The Truthmaker Problem for Presentism is discussed (although not always by that name) by various writers. See for example Bigelow, "Presentism and Properties;" Sider, Four-Dimensionalism, pp. 35-42; and Keller, "Presentism and Truthmaking." 
Eternalism: What exists does not change over time. The objects that exist at any time, $t$, include all the objects that are located at $t$, all the objects that are located at any time earlier than $t$, and all the objects that are located at any time later than $t$.

The Growing Block Theory: What exists is liable to change over time. For any time, $t$, the objects that exist at $t$ are all and only the objects that are located either at $t$ or at any time earlier than $t$.

According to the Presentist, temporal location and existence are necessarily tied together. On this view, it is never the case that an object exists at a time without being located at that time.

The Eternalist, on the other hand, holds that temporal location and existence are not necessarily tied together. It is quite possible, according to Eternalism, for an object to exist at a time even though it is not located at that time, just as it is possible for an object to exist at a place without being located at that place. For the Eternalist, the correct ontology does not change from one time to the next, just as it does not change from one spatial location to another.

Meanwhile, the proponent of The Growing Block Theory maintains that temporal location and existence are tied together, in a very specific way. In order to exist at a time, $t$, an object must be located either at $t$ or at some time earlier than $t$. So according to this theory, the correct ontology does change over time, but always by addition, never by subtraction.

\section{The Truthmaker Problem}

So much for our formulations of Presentism and its main rivals. I now turn to a characterization of The Truthmaker Problem for Presentism. (The problem is primarily a problem for Presentism, although there is a version of it that applies to The Growing Block Theory. In order to keep the discussion here a bit more streamlined, however, I will focus only on the problem as it applies to Presentism.) The Truthmaker Problem concerns an apparent conflict between Presentism and a deservedly popular idea about the connection between what is true and what exists. One way to capture this idea is in terms of supervenience. We could say, for example, that truth supervenes on being, in the sense that any two worlds that differ with respect to what is true must also 
differ with respect to what exists (or else with respect to the pattern of instantiations of universals by what exists). ${ }^{4}$

Another way to capture the popular idea about the connection between what is true and what exists is in terms of the need for truthmakers for every truth, where truthmakers are the things ${ }^{5}$ that make the relevant sentence or proposition true. ${ }^{6}$ For example, if it is true that my shirt is blue, then the truthmakers for this truth include my shirt, the property of blueness, and (perhaps) the fact that the shirt is blue (that is, the shirt's instantiation of blueness). Here is one way to formulate such a principle.

The Truthmaker Principle: For every truth, $p$, there exist some things, $x_{1-} x_{n}$, such that $p$ is true in virtue of the existence and arrangement of $x_{1}-x_{n}{ }^{7}$

A side note on the metaphysics of truth: I happen to prefer to think about truth and truthmakers in terms of propositions (the things that are true) and facts (the instantiations of universals that are the truthmakers for true propositions). But in this paper I will leave that metaphysical background aside, and instead talk in a neutral way about sentences and their truthmakers, without specifying what exactly those truthmakers must be like. But note that if pressed, I would spell out talk about truths and their truthmakers in terms of my preferred background metaphysics of propositions and facts.

It should be clear that there is at least an apparent conflict between Presentism and The Truthmaker Principle. To see why, consider the following sentences, both of which it would be natural to characterize as true right now. ${ }^{8}$

(1) There used to be dinosaurs.

\footnotetext{
4 See for example Lewis, "Truthmaking and Difference-Making."

5 Or perhaps the stuff.

${ }^{6}$ See for example Cameron, "Truthmakers."

7 I have included the word 'things' in this formulation of The Truthmaker Principle for stylistic reasons, but for a version of the principle that is neutral between a thing ontology and a stuff ontology we could simply delete that word, while allowing our quantifiers to range over both things and stuffs.

8 These examples are from Sider, Four-Dimensionalism.
} 
In 1,000 years there will be human outposts on Mars.

The Eternalist can say that (1) is made true by the existence of some past dinosaurs. That is, the Eternalist can say that the currently correct ontology contains some dinosaurs, which are not located at the present time but are located at certain earlier times, and that these past dinosaurs are the truthmakers for the current truth of the proposition expressed by (1). Likewise, the Eternalist can say that (2) is made true by the existence of some future Martian outposts. That is, the Eternalist can say that the currently correct ontology contains some Martian outposts, which are not located at the present time but are located at certain later times, and that these future settlements are the truthmakers for the current truth of (2). But the Presentist cannot say anything like these things, because according to Presentism, the currently correct ontology contains neither past dinosaurs nor future Martian outposts.

Before we try to solve this problem, we should note that there is an important distinction between The Truthmaker Problem and another difficulty for Presentism, namely, The Problem of Singular Propositions About Non-present Objects. The latter problem concerns such sentences as 'Socrates was wise', which on the face of it express singular propositions about non-present objects - objects that do not appear in the Presentist's ontology. ${ }^{9}$ I won't say anything else here about the latter problem (although I do attempt to solve it in the paper cited in the previous footnote), except to note that, since The Truthmaker Problem is meant to be a separate problem for the Presentist, we should consider it to be a problem that can be characterized in terms of purely general propositions.

\section{A Quasi-Deterministic Solution to The Truthmaker Problem}

Let's start by considering some "easy" truths about the past and the future, which I believe can point the way toward a general solution to our problem. Here are some examples of what appear to be no-brainers.

(3) Five seconds ago the moon was more than a mile from the earth.

\footnotetext{
${ }^{9}$ For more on The Problem of Singular Propositions About Non-present Objects see Markosian, "A Defense of Presentism."
} 
(4) Five seconds from now the moon will be more than a mile from the earth.

Notice, by the way, that there is no problem with the subjects of the relevant propositions not existing. For the moon, the earth, and the relation more than a mile from are all entities that exist right now. So let's assume that the relevant propositions exist, and are in fact true right now. But what could make such propositions true, according to the Presentist?

I think it is very plausible to say that the truthmakers for both of these propositions include (i) the earth, (ii) the moon, (iii) their current arrangement, and (iv) the laws of nature governing these things. For the laws of nature are presumably deterministic enough to ensure that it is a consequence of those laws, together with the current arrangement of things, that the moon was over a mile from the earth five minutes ago; and, likewise, the laws of nature are presumably deterministic enough to ensure that it is a consequence of those laws of nature, together with the current arrangement of things, that the moon will be over a mile from the earth five minutes into the future. (We will shortly consider the possibility that the laws of nature and the current arrangement do not entail either that the moon was over a mile away from the earth five minutes ago or that the moon will be over a mile away from the earth five minutes from now.) Thus, on the assumption that the laws of nature are sufficiently deterministic in the relevant ways, it seems that there are enough things in the Presentist's ontology to serve as truthmakers for these easy truths.

But now suppose that similar remarks apply to our earlier examples:

(1) There used to be dinosaurs.

(2) In 1,000 years there will be human outposts on Mars.

That is, suppose that the laws of nature are deterministic enough to entail (in conjunction with the current arrangement of things) that there used to be dinosaurs, and also that there will be human outposts on Mars in 1,000 years. Then there will be adequate truthmakers in the Presentist's ontology to make (1) and (2) both true right now. Moreover, on the supposition that the laws of 
nature are not sufficiently deterministic, in the relevant sense, then I think we should say that those sentences are false right now. ${ }^{10}$

This is the short version of my proposed solution to The Truthmaker Problem. If things now are such that it is a deterministic matter that there will be Martian outposts in 1000 years, then I say let (2) be true now. Otherwise, I say, let (2) be false now. And similarly with sentences like (1). In this way, the truth about the past and the future will be determined by the way present things are right now, in accordance with Presentism and The Truthmaker Principle.

The long version of my solution involves giving a semantics for the account of the truth about the past and the future that I am proposing. In order to see how the relevant semantics will work, we first need to consider the standard semantics for tensed sentences. In order to do that, we'll assume the "tensed" conception of semantics, according to which the bearers of truth and falsity are to be assigned truth values at times, and also according to which the past and future tenses are ineliminable features of language. ${ }^{11}$ (I take both components of this tensed conception of semantics to be required for Presentists, and indeed for anyone who endorses The A Theory of time.) In order to keep things simple, let's take sentences to be the bearers of truth and falsity, and let's deal only with general (as opposed to singular) sentences. Let's also assume that for every time, $t$, and every present-tensed, general sentence, $\varphi$, either $\varphi$ is true at $t$ or else $\varphi$ is false at $t$. Whether $\varphi$ is true or false at $t$ will of course depend on the present-tensed facts at $t$. (Let presenttensed facts be facts involving only the intrinsic properties of, and relations among, present objects.)

We'll also need to have some tense operators in our language - sentential operators that correspond to 'it has been the case that', 'it will be the case that', and their metric variants. Here are some of the standard tense operators.

10 For similar proposals, at least with respect to future-tensed sentences, see Peirce, Collected Papers of C.S. Peirce, 5.459 and 6.368; Lukasiewicz, "On Determinism;" Prior, Past, Present and Future, Ch. VII; and Thomason, "Indeterminist Times and Truthvalue Gaps."

11 For a more detailed exposition of the tensed conception of semantics, see Markosian "How Fast Does Time Pass?" 
$\mathrm{P} \varphi=$ it has been the case that $\varphi$

$\mathrm{F} \varphi=$ it will be the case that $\varphi$

$\operatorname{Pn} \varphi=$ it has been the case $n$ time units ago that $\varphi$

$\mathrm{F}_{\mathrm{n}} \varphi=$ it will be the case in $\mathrm{n}$ time units that $\varphi$

What I have described so far is a system of tense logic of the type developed by the father of tense logic, Arthur Prior. ${ }^{12}$ One crucial element of any model in the traditional semantics for such a system is a line consisting of points that represent moments of time. For each such point, $p$, and for each present-tensed sentence, $\varphi, \varphi$ is assigned a truth value at $p$. Then the truth values of tensed sentences, like $F \varphi$ and $F_{3} \varphi$, are determined by truth conditions like the following. ${ }^{13}$

$\mathrm{F} \varphi$ is true at $p$ iff $\varphi$ is true at some point to the right of $p$.

$\mathrm{F}_{3} \varphi$ is true at $p$ iff $\varphi$ is true at the point three units to the right of

$p$.

Now we are in a position to appreciate the problem for the Presentist with the standard semantics for a system of tense logic. Let ' $\mathrm{m}$ ' stand for the present-tensed sentence 'there are human outposts on Mars'. And let us assume that 'there are human outposts on Mars' is false right now but will be true in 1000 years. Finally, consider a model that contains the following line segment (with po representing the present time).

\begin{tabular}{ll}
$\begin{array}{ll}\mathrm{F}_{1000 \mathrm{~m}} \\
\sim \mathrm{m}\end{array}$ & $\mathrm{m}$ \\
\hline $\mathrm{p}_{0}$ & $\mathrm{p}_{1000}$
\end{tabular}

Figure 1

12 See, for example, Prior, Past, Present, and Future.

13 For stylistic reasons I will ignore the use/mention distinction in much of what follows. But I hope that in each case my meaning will be clear from the context. 
On the standard semantics for tensed sentences, if $\mathrm{F}_{1000 \mathrm{~m}}$ is true at $\mathrm{p}_{0}$, as it is in our model, then this will be in virtue of the fact that $m$ is true at $p_{1000}$, the point 1000 units to the right of po. But of course it is clear that if, in our model, $\mathrm{m}$ is true at $\mathrm{p}_{1000}$, then this is the case in virtue of Martian outposts that exist 1000 years from now. In short, if sentence (2) is true right now, then, according to the standard semantics for tense logic, its truth is "grounded" by the existence of future Martian outposts. And it is equally clear that this is a problem for Presentists, since we don't have any future Martian outposts in our ontology.

My proposed solution is to say that if (2) is true right now, then that is in virtue of the way present objects are right now. Here is a crucial assumption behind my solution.

Crucial Assumption: The totality of present-tensed facts at any given time is sufficient to determine a unique set of laws of nature that govern the world.

No doubt making this assumption will have some bearing on what we can and cannot say about the nature of the laws of nature. Personally, I like the socalled "Armstrong-Dretske-Tooley" account, according to which laws of nature are special, contingent relations among universals. ${ }^{14} \mathrm{I}$ think that this view of the laws will be one of the ones that is consistent with my proposed solution to the truthmaker problem. But if it is not, then I am willing to go looking elsewhere for an account of the laws of nature. In any case, we should note that my proposal comes with some commitments.

Now, either the laws of nature are deterministic or else they are not. If the laws are deterministic, then the line segment in Figure 1 corresponds to the way things are in the actual world, and the current present-tensed facts are sufficient to determine that $\mathrm{F}_{1000 \mathrm{~m}}$ is true (since in that case the present-tensed facts entail that there is only one nomically possible way things could be in 1000 years).

Suppose on the other hand that the laws of nature are indeterministic. Then there are three further possibilities: either (a) every nomically possible future is such that it involves Martian outposts in 1000 years, (b) some nomically possible futures involve Martian outposts in 1000 years and some

\footnotetext{
14 See Armstrong, What is a Law of Nature?; Dretske, "Laws of Nature;" and Tooley,
} "The Nature of Laws." 
don't, or (c) every nomically possible future is such that it involves no Martian outposts in 1000 years. These three possibilities can be captured by the following simplified models.

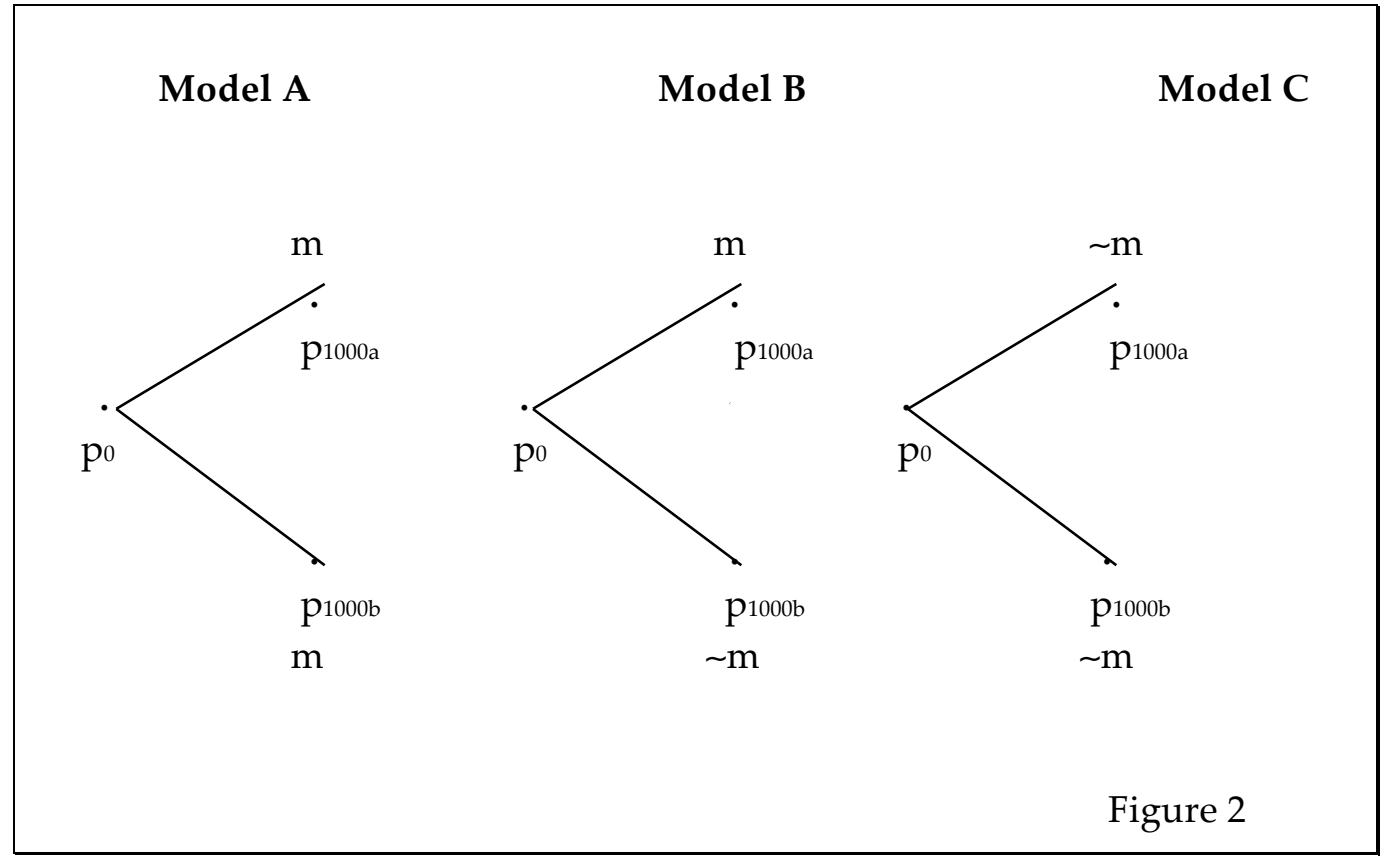

My proposal is that in Model A, Frooom should be true at $\mathrm{p}_{0}$, since the totality of present-tensed facts at that point entails that every nomically possible future is such that there are Martian outposts 1000 years after po. I also propose that in Model B, F100om should be false at $\mathrm{p}_{0}$, since it is not the case that the totality of present-tensed facts at that point entails that every nomically possible future is such that there are Martian outposts 1000 years after $\mathrm{p}_{0}$. (Note that an alternative way to go here would be to say that F1000m is neither true nor false at $\mathrm{p}_{0}$. Personally, I prefer to say that 'false' just means not true, rather than allowing truth-value gaps. But it should be clear that there is also available a truth-value-gap version of the proposal I am making. ${ }^{15}$ ) And finally, I propose that in Model C, F100om should be false at $p_{0}$ (and in fact $\mathrm{F}_{1000} \sim \mathrm{m}$ should be true at $\mathrm{p}_{0}$ ), since the totality of present-tensed facts at that

15 For examples of such proposals, see Prior, Past, Present and Future, Ch. VII; and Thomason, "Indeterminist Time and Truth-value Gaps." 
point entails that every nomically possible future is such that it is not the case that there are Martian outposts 1000 years after $\mathrm{p}_{0}$.

Notice that on my proposal, the possibility of indeterminism with respect to the past will force us to allow models with line segments that branch in the direction of the past as well as the future, as illustrated by Figure 3.16

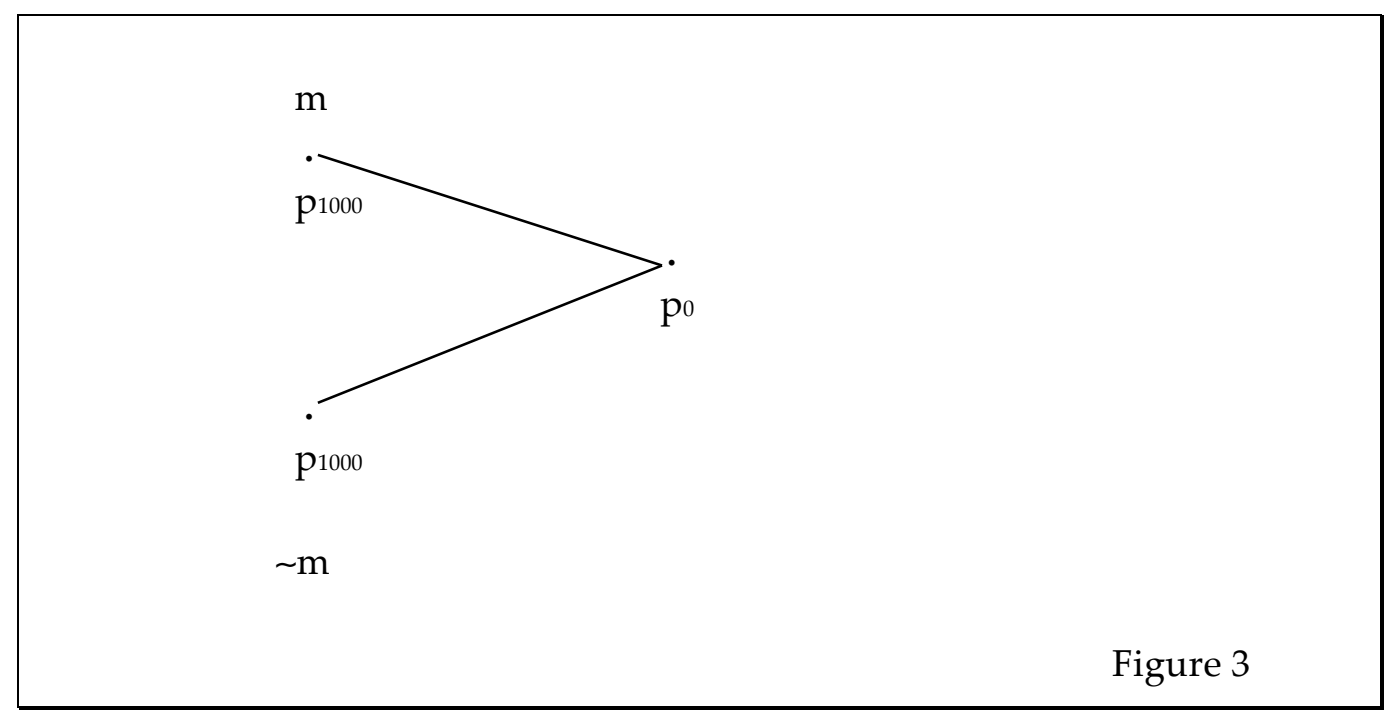

This may be taken by some to be a bad consequence of my proposal, but it is actually a consequence that I embrace. For on my view, if some sentence about the past is true, then it must be true in virtue of the way things are now. And I don't know what else besides current facts, including the laws of nature, could make such a sentence true now.

\section{A Potential Glitch}

There are various objections to such a proposal, several of which I will discuss shortly. But first I want to talk about a certain potential glitch for the proposal. Consider a model that contains the following line segment, with truth values for the present-tensed sentence $\varphi$ as indicated.

\footnotetext{
16 For more on indeterminism with respect to the past and the idea of an open past, see Lukasiewicz, "On Determinism;" and Markosian, "The Open Past."
} 


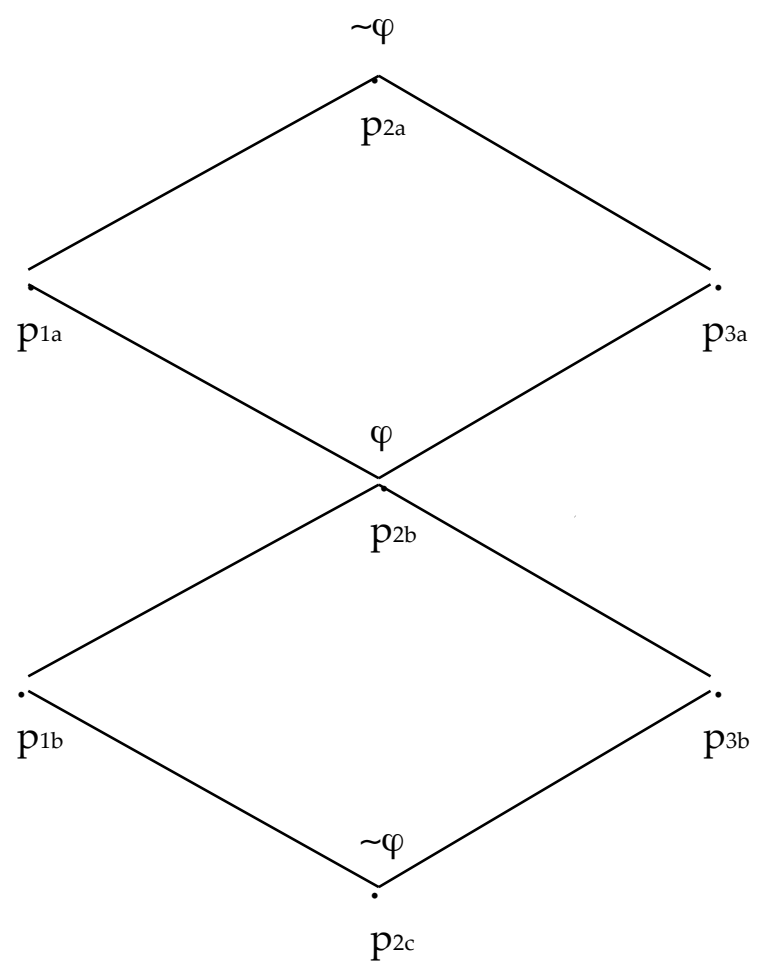

Figure 4

The way I have so far characterized my proposal suggests that it should involve the following truth conditions.

$\mathrm{P}_{1} \varphi$ is true at $p$ iff $\varphi$ is true at every point one unit to the left of $p$.

$\mathrm{F}_{1} \varphi$ is true at $p$ iff $\varphi$ is true at every point one unit to the right of $p$.

But these truth conditions yield the result that in a model containing the above line segment, $\mathrm{P}_{1} \mathrm{~F}_{1} \varphi$ is false at $\mathrm{p}_{2} \mathrm{~b}$, even though $\varphi$ itself is true at that point. (The reason why $\mathrm{P}_{1} \mathrm{~F}_{1} \varphi$ will be false at $\mathrm{p}_{2 \mathrm{~b}}$ is that not every point one unit left of $p_{2 b}$ is such that $F_{1} \varphi$ is true at it. (In fact, neither one of the two points one unit left of $\mathrm{p}_{2 \mathrm{~b}}$ has this feature.)) In other words, according to these truth conditions, even though $\varphi$ is true at $\mathrm{p}_{2 \mathrm{~b}}$, it is not true at that point that it 
was the case one time unit ago that it will be the case one time unit hence that $\varphi$.

This strikes me as a very bad result. For even if we restrict our attention at $p_{2 b}$ to things that are present at that point, we will still find things in virtue of which $\mathrm{P}_{1} \mathrm{~F}_{1} \varphi$ should be true at that point, namely, whatever it is in virtue of which $\varphi$ is true at that point.

\section{A Solution}

Luckily there is a way to solve this problem. The solution involves giving truth conditions for tensed sentences that avoid this bad result. And the key to doing so is to give truth conditions for tensed sentences that incorporate the notion of a route through the line segment in any model.

Intuitively, a route is a possible course of history that is represented by a single, non-branching line that passes through the (possibly) branching line of the model, and that never "doubles back" on itself. So for example, in the model represented by Figure 4 above, there are exactly four routes that pass through point $\mathrm{p}_{2 \mathrm{~b}}$ : (i) one that includes the points $\mathrm{p}_{1 \mathrm{a}}, \mathrm{p}_{2 \mathrm{~b}}$, and $\mathrm{p}_{3 \mathrm{a}}$, (ii) one that includes the points $\mathrm{p}_{1 \mathrm{a}}, \mathrm{p}_{2} \mathrm{~b}$, and $\mathrm{p}_{3 \mathrm{~b}}$, (iii) one that includes the points $\mathrm{p}_{1 \mathrm{~b}}, \mathrm{p}_{2} \mathrm{~b}$, and $\mathrm{p}_{3 a}$, (iv) and one that includes the points $\mathrm{p}_{1 b}, \mathrm{p}_{2 b}$, and $\mathrm{p}_{3 \mathrm{~b}}$.

Then the idea will be that in working out the truth conditions for a tensed sentence at a point, we will take into account only those points that are on routes that pass through the first point (the point of evaluation). Moreover, if we are dealing with multiple tense operators, as in sentences like $\mathrm{P}_{1} \mathrm{~F}_{1} \varphi$, so that we have to move first backward and then forward along the line segment in our model, then we must be sure always to move forward on the same route we took to go back, and similarly always to move backward on the same route we took to go forward. The best way to ensure this is to introduce the notion of truth on a route.

Truth on a route can be defined in terms of regular truth for present-tensed sentences, as follows. (Recall that we are assuming that for each presenttensed sentence, $\varphi$, and each point, $p$, either $\varphi$ is true at $p$ or else $\varphi$ is false at $p$. (Actually, what we assumed earlier was that for each time, $t$, and presenttensed sentence, $\varphi$, either $\varphi$ is true at $t$ or else $\varphi$ is false at $t$. But now that we are dealing with branching line segments, the natural way to capture the same idea is to say that each present-tensed sentence has a truth value at each point.)) 
For any present-tensed sentence, $\varphi$, route, $r$, and point, $p$, such that $p$ is on $r, \varphi$ is true-on- $r$ at $p=\mathrm{df} \varphi$ is true at $p$.

Then truth on a route can be defined for past- and future-tensed sentences in terms of truth on a route for present-tensed sentences. Here are some examples of how these definitions will go.

For any future-tensed sentence, $\mathrm{F} \varphi$, route, $r$, and point, $p$, such that $p$ is on $r, \mathrm{~F} \varphi$ is true-on- $r$ at $p=\mathrm{df} \varphi$ is true-on- $r$ at some point on $r$ that is to the right of $p$.

For any future-tensed sentence, $\mathrm{F}_{1} \varphi$, route, $r$, and point, $p$, such that $p$ is on $r, \mathrm{~F}_{1} \varphi$ is true-on- $r$ at $p=\mathrm{df} \varphi$ is true-on- $r$ at the point on $r$ one unit to the right of $p$.

Finally, we can make use of the notion of truth on a route in order to give truth conditions like the following for tensed sentences.

$\mathrm{F}_{1} \varphi$ is true at $p$ iff for every route, $r$, through $p, \mathrm{~F}_{1} \varphi$ is true-on- $r$ at $p$.

$\mathrm{P} \varphi$ is true at $p$ iff for every route, $r$, through $p, \mathrm{P} \varphi$ is true-on- $r$ at $p$.

In fact, if we wanted to be super-efficient, we could give just one generic truth condition for all the tense operators:

For any tense operator, $T$, sentence, $\varphi$, and point, $p, T \varphi$ is true at $p$ iff for every route, $r$, through $p, T \varphi$ is true-on- $r$ at $p$.

These truth conditions will avoid the bad result mentioned above. That is, they will ensure that if $\varphi$ is true at a point, $p$, then $\mathrm{P}_{1} \mathrm{~F}_{1} \varphi$ will also be true at that point. In fact, happily, these truth conditions will guarantee that for any sentence, $\varphi$, point, $p$, and number, $n$, if $\varphi$ is true at $p$ then both $\mathrm{P}_{n} \mathrm{~F}_{n} \varphi$ and $\mathrm{F}_{n} \mathrm{P}_{n} \varphi$ will also be true at $p$. (And similarly with various other, multiply tensed sentences of the relevant kind.)

\section{Objections}

There are at least three main objections that are likely to raised against this proposal. The first objection has to do with the possibility of wildly 
indeterministic laws of nature. ${ }^{17}$ Suppose, the objection goes, the laws of nature governing our world are wildly indeterministic with respect to the past. Suppose, in particular, that it is a consequence of quantum physics that there is a certain non-zero probability that all of the current particles in the universe sprang into existence, from nothing, a mere five minutes ago. Then on the proposal I am making, it is not true that you and I and the rest of the universe existed five minutes ago. Nor is it true that five minutes ago you were reading a paper on Presentism. But, it will be objected, these consequences sound absurd.

My reply to this objection is that I don't think the relevant consequences are so absurd. For I think Presentism is true, and I endorse the above principle about truth requiring truthmakers. So I don't see how there could be truths about the past that are not grounded in the way present things are. Put another way: If there were the kind of truths that the objector wants here, then they would be ungrounded truths, hanging in mid-air with nothing to support them. And that is something that I find spooky. So I think the upshot is that if it turns out that the laws of nature are wildly indeterministic in the relevant way, then we do (and should) have a paucity of truths about the past.

It is worth noting, however, that my earlier choice of bivalence over other alternatives is especially relevant here. Perhaps some people will find it much more palatable to invoke degrees of truth between 0 and 1, which will allow us to say, for example, that it is true to degree .99 that all the current particles (or at least many of them) have existed for more than five minutes. Similarly, this approach will allow us to say that it is true to degree .99 that you were reading a paper on Presentism five minutes ago, even in the imagined scenario.

The second objection that is likely to be raised against my proposal concerns what is sometimes called the "relevance constraint" on truthmakers, according to which the truthmaker(s) for a sentence must be whatever it is that the sentence is about. ${ }^{18}$ Take for instance our first example:

17 I am grateful to Peter Forrest for pressing this objection during a presentation of an earlier version of this paper.

18 See for example Smith, "Truthmaker Realism;" and Merricks, Truth and Ontology (esp. p. 29). I am grateful to Andrea Borghini and Giuliano Torrengo for raising this objection. 
(1) There used to be dinosaurs.

According to the objection, if (1) is true, then it must be made true by past dinosaurs, and not by present-day objects and current laws of nature.

My response to this objection is in two parts. Here is the first part. Sentence (1) is a past-tensed sentence with an existential quantifier inside the scope of a tense operator. So the sentence has this form:

(1a) It has been the case that there is an $x$ such that $x$ is a dinosaur. ${ }^{19}$

But notice that, grammatically speaking, the subject of (1a) is 'it'. (1a) says that it has been a certain way (namely, such that there are dinosaurs). And what is the referent of 'it' in this sentence? I don't think it is a bunch of past dinosaurs. I think it is the world.

Compare (1a) with this sentence:

(5) It's possible that there is a purple cow.

Most of us will want to say that (5) is true. But what are its truthmakers? There are two main views about the metaphysics of modality that are relevant here. The majority view (by, as it happens, an overwhelming majority) among contemporary metaphysicians is Modal Actualism, according to which (roughly) only actual objects exist, and talk of mere possibilia is to be understood in terms of such abstract objects as possible worlds (normally construed as maximal, consistent propositions) or qualitative properties. ${ }^{20} \mathrm{On}$ this view, the subject of a sentence like (5) is the actual world (together with its contents), and the truthmakers for this sentence are various actual objects, but never any non-actual objects.

The other main view about the metaphysics of modality is Modal Realism, according to which non-actual objects, like my numerous possible sisters, are just as real as actual objects, like my four actual brothers. ${ }^{21}$ On this view, the subject of (5) is the domain of all possible worlds, and the truthmakers for (5) are very real, albeit non-actual, purple cows.

19 Or better still: (1b) It has been the case that there is an $x$ and there is a $y$ such that $x$ and $y$ are dinosaurs.

20 See for example Plantinga, The Nature of Necessity.

21 See for example Lewis, On the Plurality of Worlds. 
Now, should we think that the Modal Actualist is in trouble because her view violates the relevance constraint on truthmakers, insofar as the truthmakers for (5) do not include any purple cows? I think the answer is clearly No. Unless the minority position - Modal Realism - is correct, we should be happy to say that the subject of (5) is 'it', which refers to the world, and that it is the world and its contents that make (5) true. Meanwhile, as has often been emphasized, ${ }^{22}$ Presentism is analogous to Modal Actualism, while its main rival, Eternalism, is analogous to Modal Realism. Given these facts, I think it is extremely natural and plausible for the Presentist to say that the truthmakers for (1) and (1a) are the present world and its contents (rather than any past dinosaurs), as suggested above.

I mentioned earlier that my response to the relevance-constraint objection came in two parts. The second part is simpler and shorter than the first part. It consists merely of the observation that if my opponent is going to insist that the truthmakers for (1) and (1a) must be whatever it is that those sentences are about, and also that the sentences in question are about non-present dinosaurs, and if I am going to go along with these claims, then, well, I'm not a very good proponent of my position. In short, the relevance-constraint objection to my solution to The Truthmaker Problem for Presentism ought not to convince anyone who is already committed to Presentism, since it requires a combination of claims that no self-respecting Presentist should accept.

The third main objection that is likely to be raised against my proposed solution to The Truthmaker Problem concerns a consequence of the semantics I have offered for tensed sentences that I went to a lot of trouble to secure, namely, that if $\varphi$ is true at some point, then $\mathrm{P}_{1} \mathrm{~F}_{1} \varphi$ is also true at that point. The objection could be made by someone giving the following speech. ${ }^{23}$

Okay, you have convinced me that the only way a futuretensed sentence like 'It will be the case in one day that it is raining' could be true at a time is if it is a deterministic matter at that time that it will be raining in one day. So suppose that things are in fact indeterministic enough on Tuesday to ensure that this future-tensed sentence is not true, on your view. That is, suppose that on Tuesday, the following day's weather is still

\footnotetext{
22 See for example Markosian, "A Defense of Presentism."

${ }^{23}$ I am grateful to Ted Sider for raising this objection in conversation.
} 
"up in the air." So far so good. But then suppose that Wednesday rolls around, and sure enough it rains. Then on your view, the sentence 'It was the case one day ago that it will be the case one day hence that it is raining' is true on Wednesday. But that seems to go against the intuition that you originally appealed to, according to which it was not true on Tuesday that it was going to be the case that it is raining on Wednesday. It's as if Wednesday's rain has all of a sudden washed away the previous day's indeterminism!

Here is my reply. We must distinguish between two similar but importantly different things that could be said on Wednesday. The first is "It was the case one day ago that it will be the case one day hence that it is raining." This is an object-language utterance with iterated tense operators, and it is true on Wednesday in the imagined scenario, according to the semantics I am proposing for tensed sentences. And the reason this sentence is true on Wednesday, despite the fact that things were still up in the air on Tuesday, is that Wednesday's falling rain is truthmaker enough to make it true.

Meanwhile, the second thing that could be said on Wednesday is "The sentence 'It will be the case in one day that it is raining' was not true yesterday." This is a meta-language utterance concerning the truth value of a particular tensed sentence on Tuesday, and it is also true. And the reason this meta-language sentence is true on Wednesday, despite the concurrent truth of the object-language sentence mentioned in the previous paragraph, is that on Wednesday, things are such that it was not a deterministic matter one day earlier that it would be raining.

Because these two things that can both be said on Wednesday are different claims, in different languages, concerning different topics, the truth of the latter claim (the meta-language one) does not undermine the truth of the former claim (the object-language one). ${ }^{24}$ Wednesday's rain guarantees the

24 It is worth noting, however, that in making this reply to the objection, I am committing myself to a rejection of the principle that if $\mathrm{P}_{1} \mathrm{~F}_{1} \varphi$ is true at a point, $p$, then $F_{1} \varphi$ must also be true at every point one unit to the left of $p$. But the rejection of such "disquotation-like" principles was already built into the semantics for tensed sentences being offered here. 
truth of the claim that it was going to rain, but it does not thereby wash away the previous day's indeterminism. All is well. ${ }^{25}$

\section{References}

Armstrong, David, What is a Law of Nature? (Cambridge University Press, 1983).

Bigelow, John, "Presentism and Properties," in Tomberlin, James (ed.), Philosophical Perspectives 10 (Blackwell, 1996), pp. 35-52.

Cameron, Ross, "Truthmakers," in Glanzberg, Michael (ed.), The Oxford Handbook of Truth (Oxford University Press, forthcoming).

Dretske, Fred, “Laws of Nature," Philosophy of Science 44 (1977), pp. 248-268.

Keller, Simon, "Presentism and Truthmaking," in Zimmerman, Dean (ed.), Oxford Studies in Metaphysics 1 (Oxford University Press, 2004), pp. 83-104.

Lewis, David, On the Plurality of Worlds (Basil Blackwell, 1986).

Lewis, David, "Truthmaking and Difference-Making," Noûs, 35 (2001), pp. 602-615.

25 Earlier versions of this paper were presented at the University of Leeds and the University of Sydney in 2005. I am grateful to both audiences for helpful discussions. Also, the core ideas of this paper appeared in my 1990 doctoral dissertation at the University of Massachusetts. I am grateful to the members of my dissertation committee - Gary Matthews, Fred Feldman, Ed Gettier, and Angelika Kratzer - and also to David Cowles, Cranston Paull, Tom Ryckman, and Ted Sider for helpful discussions. I am also grateful to Andrea Borghini, Giuliano Torrengo, and an anonymous referee for comments on the penultimate draft. 
Lukasiewicz, Jan, "On Determinism," in McCall, Storrs (ed.), Polish Logic (Oxford University Press, 1967), pp. 19-39.

Markosian, Ned, "A Defense of Presentism," in Zimmerman, Dean (ed.), Oxford Studies in Metaphysics 1 (Oxford University Press, 2004), pp. 47-82.

Markosian, Ned, "How Fast Does Time Pass?" Philosophy and Phenomenological Research 53 (1993), pp. 829-844.

Markosian, Ned, “The Open Past,” Philosophical Studies 79 (1995), pp. 95-105.

Merricks, Trenton, Truth and Ontology (Oxford University Press, 2007).

Peirce, Charles Sanders, Collected Papers of C.S. Peirce (Harvard University Press, 1934).

Plantinga, Alvin, The Nature of Necessity (Oxford University Press, 1974).

Prior, Arthur, Past, Present and Future (Clarendon Press, 1967).

Sider, Theodore, Four-Dimensionalism (Oxford University Press, 2001).

Smith, Barry, "Truthmaker Realism," Australasian Journal of Philosophy 77 (1999), pp. 274-291.

Thomason, Richmond, "Indeterminist Time and Truth-value Gaps," Theoria 36 (1970), pp. 264-281.

Tooley, Michael, “The Nature of Laws,” Canadian Journal of Philosophy 7 (1977), pp. 667-698. 